\title{
Molecular double chains and 3-D supramolecular frameworks with open channels assembled from 1D copper(II) maleate coordination polymers with chelating aromatic amine ligands by noncovalent interactions
}

\author{
Ping Liu ${ }^{\text {a }}$, Yao-Yu Wang a,*, Dong-Sheng Li ${ }^{\text {a }}$, Hai-Rui Ma ${ }^{\text {a }}$, Qi-Zhen Shi ${ }^{\text {a }}$ \\ Gene-Hsiang Lee ${ }^{b}$, Shie-Ming Peng ${ }^{b}$ \\ ${ }^{a}$ Department of Chemistry/Shaanxi Key Laboratory of Physico-Inorganic Chemistry, Northwest University, Xi'an, Shaanxi 710069, PR China \\ ${ }^{\mathrm{b}}$ Department of Chemistry, National Taiwan University, Taipei, Taiwan
}

Received 20 March 2005; received in revised form 24 May 2005; accepted 24 May 2005

Available online 7 July 2005

\begin{abstract}
Two $1 \mathrm{D}$ coordination polymers, $[\mathrm{Cu}(\mathrm{mal})(\mathrm{Hdpa})]_{n}(\mathbf{1})$ and $\left\{[\mathrm{Cu}(\mathrm{mal})(\mathrm{tpy})] \cdot 4 \mathrm{H}_{2} \mathrm{O}\right\}_{n}(\mathbf{2})\left(\mathrm{mal}=\right.$ maleate, Hdpa $=2,2^{\prime}$-dipyridylamine and tpy $=2,2^{\prime}: 6^{\prime}, 2^{\prime \prime}$-terpyridine), have been synthesized and their crystal structures, IR spectra, thermal analyses, magnetic properties were determined. In 1 and 2, the maleate ligands link adjacent metal centers to form 1D coordination polymeric chains. Furthermore, the carboxylate oxygen atoms and the aromatic chelate ligands provide potential supramolecular recognition sites for noncovalent interactions to form higher dimensionality. In 1, each pair of 1D chains recognize each other through strong hydrogen bond formed by active amine (-NH-) hydrogen and aromatic $\pi-\pi$ stacking interactions to generate a zipperlike double-stranded chain. In contrast, when the substitutions of tpy for dpa further enhance the $\pi-\pi$ aromatic stacking interactions, complex 2 is directly constructed into $2 \mathrm{D}$ zipperlike layers by the unprecedented aromatic $\pi-\pi$ stacking interactions that same orientated aromatic chelate ligands are simultaneously attached to both sides of the chain and the significant $\mathrm{C}-\mathrm{H}$. . O hydrogen bonds. These layers are constructed through hydrogen bonds and result in a 3D supramolecular network with 1D open channels, in which exists an unprecedented one-dimensional water chain. Both were magnetically characterized, showing weak ferromagnetic behavior.

(C) 2005 Elsevier B.V. All rights reserved.
\end{abstract}

Keywords: Copper; Coordination polymers; Magnetism; Supramolecular

\section{Introduction}

Organic-inorganic hybrid materials have been studied for their intriguing topologies and potential applications in gas storage, catalysis, separations, and molecular recognition [1]. Only very recently have attempts been made to combine both coordination bonds and weaker non-covalent forces such as hydrogen bond-

\footnotetext{
* Corresponding author. Tel.: +86 29883 03097; fax: +86 29883 73398.

E-mail address: wyaoyu@nwu.edu.cn (Y.-Y. Wang).
}

ing and $\pi-\pi$ contacts to crystal engineer organic-inorganic materials [2]. In this regard, the dicarboxylic acids are good candidate as bridging ligands for designing new organic-inorganic hybrid materials as it may participate in both types of interaction as well as their diverse coordination modes. Furthermore, the dicarboxylic acids, as a superexchange pathways between the metal ions $[\mathrm{Cu}(\mathrm{II}), \mathrm{Mn}(\mathrm{II}), \mathrm{Ni}(\mathrm{II})$, etc.], have received considerable attention in the field of molecular magnetism $[3,4]$. Therefore, the dicarboxylic acids such as oxalate, malonate, terephthalate [4-6] and, to a less degree, maleate [7] are used to construct interesting molecular 
topologies and crystal packing motif. On the other hand, in spite of polycyclic aromatic ligands such as 2,2'-bipyridyl and 1,10-phenanthroline frequently being used in combination with dicarboxylates and leading to novel architectures where they facilitate supramolecular self-assembly through aromatic-aromatic $(\pi-\pi$ and $\mathrm{CH}-\pi$ ) interactions $[5 \mathrm{a}, 8]$, studies on $2,2^{\prime}$-dipyridylamine (Hdpa) or 2,2': $6^{\prime}, 2^{\prime \prime}$-terpyridine (tpy) with dicarboxylates are less reported [9]. Considering the mal and dpa/tpy may provide potential supramolecular recognition sites for noncovalent interactions to form higher dimensionality along with interesting magnetic properties of dicarboxylates, our work focused on $\mathrm{Cu}(\mathrm{mal})$ and Hdpa/tpy.

Herein, we will report the synthesis, structure characterization and magnetic characterization of two maleate bridged $\mathrm{Cu}(\mathrm{II})$ complexes $[\mathrm{Cu}(\mathrm{mal})(\mathrm{Hdpa})]_{n} \mathbf{1}$ and $\left\{[\mathrm{Cu}(\mathrm{mal})(\mathrm{tpy})] \cdot 4 \mathrm{H}_{2} \mathrm{O}\right\}_{n} 2$. The two novel coordination polymers are based on topologically identical chains where the copper centers chelated by amine ligands are linked through mal bridges. Significantly, the chains may also be interacted under direction of supramolecular recognition and attraction through $\pi-\pi$ aromatic stacking interactions and hydrogen-bonding interactions into molecular zipperlike double-stranded chains or 3D supramolecular network with 1D open channels. The most remarkable feature in $\mathbf{2}$ is that there exists hydrogen-bonding one-dimensional water chain in the open channels.

\section{Experimental}

All chemicals were purchased commercially and used as received. Elemental analyses were determined with a Perkin-Elmer model $240 \mathrm{C}$ automatic analytical instrument. IR spectra $\left(4000-400 \mathrm{~cm}^{-1}\right)$ were recorded on KBr pellets with a Nicolet 170SX FT-IR spectrometer. Differential thermogravimetric analyses (TGA) and differential scanning calorimetry (DSC) were performed on a Netzsch STA 449C microanalyzer under flowing air with a heating rate of $10^{\circ} \mathrm{C} / \mathrm{min}$. Variable-temperature (2-300 K) magnetic susceptibility measurement was carried out on a Maglab System 2000 susceptometer (made in Oxford, UK). The magnetometer was operated at $1 \mathrm{~T}$ magnetic field. The diamagnetic correction was evaluated from Pascal's constants.

\subsection{Syntheses of the complexes}

\subsection{1. $[\mathrm{Cu}(\mathrm{mal})(\mathrm{Hdpa})]_{n}($ 1)}

A suspension of maleate $\mathrm{Cu}(\mathrm{II})$ salt $(17.8 \mathrm{mg}$, $1 \mathrm{mmol}$ ) and Hdpa (19.2 mg, $1 \mathrm{mmol}$ ) in methanol solution $(10 \mathrm{~mL})$ were stirred at room temperature until all the starting materials had dissolved and were replaced with a green powdery precipitate. The mixture was fil- tered, and a green, clear solution was obtained; dark green crystals of 1 were formed upon standing of the filtrate at room temperature 2 days $(9.8 \mathrm{mg} \mathrm{28.2 \% ).} \mathrm{Anal.}$ Calc. for $\mathrm{C}_{14} \mathrm{H}_{11} \mathrm{CuN}_{3} \mathrm{O}_{4}$ (348.80): C, 48.17; H, 3.15; N, 12.04. Found: C, 48.32; H, 3.01; N, $12.20 \%$.

\subsection{2. $\left\{[\mathrm{Cu}(\mathrm{mal})(\mathrm{tpy})] \cdot 4 \mathrm{H}_{2} \mathrm{O}\right\}_{n}($ 2)}

Complex 2 was prepared similar to $\mathbf{1}$. A suspension of maleate $\mathrm{Cu}(\mathrm{II})$ salt $(17.8 \mathrm{mg}, 1 \mathrm{mmol})$ and tpy $(23.8 \mathrm{mg}$, $1 \mathrm{mmol})$ in methanol solution $(15 \mathrm{~mL})$ were stirred at room temperature until all the starting materials had dissolved and formed a dark green, clear solution that was immediately filtered; dark green crystals of $\mathbf{2}$ were formed upon standing of the filtrate at room temperature 3 days $\left(35.3 \mathrm{mg} 73.1 \%\right.$ ). Anal. Calc. for $\mathrm{C}_{19} \mathrm{H}_{21} \mathrm{Cu}-$ $\mathrm{N}_{3} \mathrm{O}_{8}$ (482.93): C, 47.21; H, 4.35; N, 8.70. Found: C, $47.32 ; \mathrm{H}, 4.20 ; \mathrm{N}, 8.66 \%$.

\subsection{X-ray crystallography}

Data collection (single crystal with dimensions of $0.15 \times 0.15 \times 0.04 \mathrm{~mm}^{3}$ for $\mathbf{1}$ and $0.536 \times 0.497 \times$ $0.332 \mathrm{~mm}^{3}$ for 2) was performed at 295(2) K for $\mathbf{1}$ and 293(2) K for 2 on a Bruker SMART APEX CCD-based diffractometer equipped with Mo $\mathrm{K} \alpha$ radiation $(\lambda=0.071073 \mathrm{~nm})$. The structures were solved by direct methods and refined by the full-matrix least-squares on $F^{2}$ with SHELXTL-PC v 5.03 software package [10]. The non-hydrogen atoms were refined anisotropically and the hydrogen atoms of the organic ligands were placed geometrically. A summary of the crystallographic data for $\mathbf{1}$ and $\mathbf{2}$ is presented in Table 1.

\section{Results and discussion}

\subsection{Description of crystal structure}

Both complexes are constructed by $1 \mathrm{D}$ chains where distorted square-pyramidal $\mathrm{Cu}(\mathrm{II})$ centers are linked by mal bridges. However, the structures significantly differ in the coordination environment, coordination modes of the mal ligands and chain packing. Selected bond lengths and angles for $\mathbf{1}$ and $\mathbf{2}$ are listed in Tables 2 and 3 , respectively.

\subsubsection{Structures of individual chains in $\mathbf{1}$ and $\mathbf{2}$}

In the complex $\mathbf{1}$, the copper atoms are coordinated to exhibit a $\mathrm{CuN}_{2} \mathrm{O}_{3}$ distorted square-pyramidal environment, the $\tau$ value being 0.230 (square-pyramidal and trigonal-pyramidal surroundings corresponding to $\tau=0$ and $\tau=1$, respectively.) [11]. The equatorial plane around $\mathrm{Cu} 1$ is build by two $\mathrm{N}$ atoms of one Hdpa ligand and two $\mathrm{O}$ atoms of two different mal ligands (the average value of $\mathrm{Cu}-\mathrm{N}$ and mean $\mathrm{Cu}-\mathrm{O}$ bonds being $1.966(5)$ and 1.979(4) $\AA$, respectively) (Fig. 1). The 
Table 1

Crystal data and structure refinement for $\mathbf{1}$ and $\mathbf{2}$

\begin{tabular}{|c|c|c|}
\hline & 1 & 2 \\
\hline Empirical formula & $\mathrm{C}_{14} \mathrm{H}_{11} \mathrm{~N}_{3} \mathrm{O}_{4} \mathrm{Cu}$ & $\mathrm{C}_{19} \mathrm{H}_{21} \mathrm{~N}_{3} \mathrm{O}_{8} \mathrm{Cu}$ \\
\hline Formula weight & 348.80 & 482.93 \\
\hline Temperature $(\mathrm{K})$ & $295(2)$ & 293(2) \\
\hline Crystal system & monoclinic & triclinic \\
\hline Space group & $P 2(1) / c$ & $P \overline{1}$ \\
\hline \multicolumn{3}{|l|}{ Unit cell dimensions } \\
\hline$a(\AA)$ & $7.1753(3)$ & $7.7302(11)$ \\
\hline$b(\AA)$ & $20.8504(9)$ & $10.9154(15)$ \\
\hline$c(\AA)$ & $8.8844(4)$ & $12.9239(18)$ \\
\hline$\alpha\left({ }^{\circ}\right)$ & 90 & $71.808(2)$ \\
\hline$\beta\left({ }^{\circ}\right)$ & $93.288(10)$ & $89.143(2)$ \\
\hline$\gamma\left({ }^{\circ}\right)$ & 90 & $88.459(2)$ \\
\hline$V\left(\AA^{3}\right)$ & $1326.99(10)$ & $1035.6(3)$ \\
\hline$Z$ & & 2 \\
\hline$D_{\text {calc }}\left(\mathrm{g} \mathrm{cm}^{-3}\right)$ & 1.746 & 1.549 \\
\hline$\mu\left(\mathrm{mm}^{-1}\right)$ & 1.669 & 1.107 \\
\hline$F(000)$ & 708 & 498 \\
\hline$\theta$ range for data collection & $2.50-25.00$ & $1.96-28.27$ \\
\hline Limiting indices & $-8 \leqslant h \leqslant 8 ;-15 \leqslant k \leqslant 24 ;-10 \leqslant l \leqslant 10$ & $-10 \leqslant h \leqslant 9 ;-14 \leqslant k \leqslant 13 ;-14 \leqslant l \leqslant 16$ \\
\hline \multirow[t]{2}{*}{ Numbers of reflections } & Total: 9005 & Total: 6203 \\
\hline & Unique:2342 $\left(R_{\mathrm{int}}=0.0506\right)$ & Unique: $4547\left(R_{\mathrm{int}}=0.0576\right)$ \\
\hline Goodness-of-fit on $F^{2}$ & 1.113 & 0.951 \\
\hline Final $R$ indices $[I>2 \sigma(I)]^{\mathrm{a}, \mathrm{b}}$ & $R_{1}=0.0621, w R_{2}=0.1658$ & $R_{1}=0.0436, w R_{2}=0.0984$ \\
\hline$R$ indices (all data) ${ }^{\mathrm{a}, \mathrm{b}}$ & $R_{1}=0.0849, w R_{2}=0.1778$ & $R_{1}=0.0532, w R_{2}=0.1013$ \\
\hline
\end{tabular}

${ }^{\mathrm{a}} R_{1}=\sum\left\|F_{\mathrm{o}}|-| F_{\mathrm{c}}\right\| / \sum\left|F_{\mathrm{o}}\right|$.

${ }^{\mathrm{b}} w R_{2}=\left[\sum w\left(F_{\mathrm{o}}^{2}-F_{\mathrm{c}}^{2}\right)^{2} / \sum w\left(F_{\mathrm{o}}^{2}\right)^{2}\right]^{1 / 2}$.

Table 2

Selected bond lengths $(\AA)$ and angles $\left(^{\circ}\right)$ for 1

\begin{tabular}{lc}
\hline Bond lengths & \\
Cu1-N1 & $1.956(5)$ \\
$\mathrm{Cu} 1-\mathrm{O} 3$ & $1.983(5)$ \\
$\mathrm{Cu} 1-\mathrm{O} 2$ & $1.975(4)$ \\
$\mathrm{Cu} 1-\mathrm{O} 1$ & $2.366(4)$ \\
$\mathrm{Cu} 1-\mathrm{N} 3$ & $1.977(5)$ \\
Bond angles & \\
$\mathrm{N} 1-\mathrm{Cu} 1-\mathrm{O} 2$ & $156.62(19)$ \\
$\mathrm{O} 2-\mathrm{Cu} 1-\mathrm{N} 3$ & $95.22(19)$ \\
$\mathrm{O} 2-\mathrm{Cu} 1-\mathrm{O} 3$ & $88.0(2)$ \\
$\mathrm{N} 1-\mathrm{Cu} 1-\mathrm{O} 1$ & $98.33(17)$ \\
$\mathrm{N} 3-\mathrm{Cu} 1-\mathrm{O} 1$ & $122.34(18)$ \\
$\mathrm{N} 1-\mathrm{Cu} 1-\mathrm{N} 3$ & $92.64(19)$ \\
$\mathrm{N} 1-\mathrm{Cu} 1-\mathrm{O} 3$ & $98.9(2)$ \\
$\mathrm{N} 3-\mathrm{Cu} 1-\mathrm{O} 3$ & $142.8(2)$ \\
$\mathrm{O} 2-\mathrm{Cu} 1-\mathrm{O} 1$ & $59.03(16)$ \\
$\mathrm{O} 3-\mathrm{Cu} 1-\mathrm{O} 1$ & $90.93(19)$ \\
\hline
\end{tabular}

Symmetry transformations used to generate equivalent atoms: A: $x-1, y, z ; \mathrm{B}: x+1, y, z$.

apical position is occupied by a maleate-oxygen atom

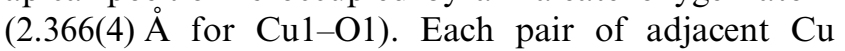
atoms is bridged by a mal ligand to form a $1 \mathrm{D}$ polymeric chain extending along [ $\left[\begin{array}{lll}0 & 0 & 1\end{array}\right]$ direction with an adjacent $\mathrm{Cu} \cdots \mathrm{Cu}$ distance of 7.1753(2) $\AA$. It can be noted that two carboxylate groups of the mal ligand have two coordination modes. In the first mode, the carboxylate group monatomically coordinates one $\mathrm{Cu}$ atom in the syn fashion (through $\mathrm{O} 3$ toward $\mathrm{Cu} 1$ ) and the other chelating one $\mathrm{Cu}$ atom (through $\mathrm{O} 1, \mathrm{O} 2$ toward $\mathrm{Cu} 1$ ). The dpa ligands are extended uniquely at one side of the chain in a parallel fashion (Fig. 1).

When tpy, a chelate aromatic ligand of a larger size, was used instead of dpa, analogous neutral 1D chains are formed in 2. As illustrated in Fig. 2, the copper atoms in 2 are five-coordinated $\mathrm{CuN}_{3} \mathrm{O}_{2}$ and have distorted square-pyramidal environment, the $\tau$ value being 0.234 . The basal sites around $\mathrm{Cu}$ atoms are occupied by three tpy-nitrogen atoms (1.939(2), 2.040(2), 2.064(2) $\AA$ for $\mathrm{Cu} 1-\mathrm{N}(1,2,3)$, respectively) and one carboxylateoxygen atom (1.9226(17) $\AA$ for Cu1-O1) from a maleate ligand. The apical position is occupied by a maleateoxygen atom, and the value of the bond length (2.1800(2) $\AA$ for Cu1-O3A) is significantly longer than the equatorial one. In $\mathbf{2}$, the environment of copper atoms is modified by incorporation of a tpy instead of dpa, resulting in change of a coordination mode of one carboxylate group from chelating to monodentate. Therefore, the maleate dianion behave as 1,4-bidentate bridging ligands, each carboxylate group as a monodentate ligand to bind a metal ion, to give an infinite line chain with the adjacent $\mathrm{Cu} \cdots \mathrm{Cu}$ distance of 7.7302(1) A. The tpy ligands are extended uniquely at one side of this chain in a slanted fashion (Fig. 2).

To the best of our knowledge, the maleate anions in $\mathbf{1}$ provide the first example of maleate to serve as a tridentate bridging ligand, one terminal carboxylate bridging one $\mathrm{Cu}$ atom and the other chelating the second $\mathrm{Cu}$ 
Table 3

Selected bond lengths $(\AA)$ and angles $\left({ }^{\circ}\right)$ for 2

\begin{tabular}{lr}
\hline Bond lengths & \\
$\mathrm{Cu} 1-\mathrm{O} 1$ & $1.9226(17)$ \\
$\mathrm{Cu} 1-\mathrm{N} 3$ & $2.064(2)$ \\
$\mathrm{Cu} 1-\mathrm{N} 2$ & $1.939(2)$ \\
$\mathrm{Cu} 1-\mathrm{O} 3 \mathrm{~A}$ & $2.1800(18)$ \\
$\mathrm{Cu} 1-\mathrm{N} 1$ & $2.040(2)$ \\
Bond angles & \\
O1-Cu1-N2 & $168.07(8)$ \\
$\mathrm{N} 2-\mathrm{Cu} 1-\mathrm{N} 1$ & $79.45(8)$ \\
$\mathrm{N} 2-\mathrm{Cu} 1-\mathrm{N} 3$ & $78.77(8)$ \\
$\mathrm{O} 1-\mathrm{Cu} 1-\mathrm{O} 3 \mathrm{~A}$ & $88.87(7)$ \\
$\mathrm{N} 1-\mathrm{Cu} 1-\mathrm{O} 3 \mathrm{~A}$ & $109.03(8)$ \\
$\mathrm{O} 1-\mathrm{Cu} 1-\mathrm{N} 1$ & $99.46(8)$ \\
$\mathrm{O} 1-\mathrm{Cu} 1-\mathrm{N} 3$ & $98.93(8)$ \\
$\mathrm{N} 1-\mathrm{Cu} 1-\mathrm{N} 3$ & $154.03(9)$ \\
$\mathrm{N} 2-\mathrm{Cu} 1-\mathrm{O} 3 \mathrm{~A}$ & $102.76(8)$ \\
$\mathrm{N} 3-\mathrm{Cu} 1-\mathrm{O} 3 \mathrm{~A}$ & $89.51(8)$ \\
\hline
\end{tabular}

Symmetry transformations used to generate equivalent atoms: A: $x+1, y, z ; \mathrm{B}: x-1, y, z$.

atom (Scheme 1(a)). From others work, we are aware that the maleate anions can function as other five bridging modes: mono-bidentate ligands to chelate one metal atom as in $\left[\mathrm{Cu}\left(\mathrm{pz}^{*}\right)_{2}(\mathrm{mal})\right] \cdot 1.5 \mathrm{H}_{2} \mathrm{O}($ Scheme 1(b)) [7a]; bis-monodentate ligands linking two metal atoms as in complex 2 (Scheme 1(c)); tridentate ligands with one carboxylate $\mathrm{O}$ atom of one end bidentately bridging two metal atoms and the other end monodentately coordinating one metal atom as in $\left[\mathrm{Cu}_{2}(\mathrm{mal})_{2}(\text { phen })_{2}\right] \cdot 4$ $\mathrm{H}_{2} \mathrm{O} \cdot 2 \mathrm{MeOH}$ (Scheme 1(d)) [7b]; tetradentate ligands with two carboxylate $\mathrm{O}$ atom of two end chelately coordinating one metal atom and the other two carboxylate $\mathrm{O}$ atom bidentately bridging two metal atoms as in $\left[\mathrm{Mn}_{4}(\mathrm{mal})_{2}(\text { bipy })_{8}\right]\left(\mathrm{ClO}_{4}\right)_{4} \cdot\left(\mathrm{H}_{2} \mathrm{O}\right)_{2}(\mathrm{MeOH})_{2} \quad($ Scheme 1(e)) [7c]; tetradentate ligands with one carboxylate $\mathrm{O}$ atom of one end bidentately bridging two metal atoms<smiles>[M]OC(=O)/C=C\C(=O)O[M]</smiles>

a<smiles>[M]OC(=O)/C=C\C(=O)O[M]</smiles>

d<smiles>[M]OC(=[VH])/C=C\C(O[M])O[M]</smiles><smiles>[M]OC(=O)/C=C\C(=O)O[M]</smiles><smiles>[M]OC(=O)/C=C\C(=O)O[M]</smiles>

c<smiles>[M]OC(=O)/C=C\C(=O)O[M]</smiles>

Scheme 1.

and the other end bidentately bridging two metal atoms as in $\left\{\left[\mathrm{Mn}(\mathrm{mal})\left(4,4^{\prime} \text {-bipy }\right)\right] \cdot 0.5\left(\mathrm{H}_{2} \mathrm{O}\right)_{2}\right\}_{n}$ (Scheme 1(f)) [7d].

\subsubsection{Chain packing and noncovalent interactions in 1 and 2}

The structures of individual chains in complex $\mathbf{1}$ and $\mathbf{2}$ are similar but different in amine ligand and coordination mode of mal. The chain packing in the structures, however, is significantly different. In complex $\mathbf{1}$, each pair of chains recognizes each other through the offset aromatic $\pi-\pi$ stacking interactions of the dpa ligands to generate a zipperlike double-stranded chain (Fig. 3). The perpendicular distances between the paired dpa ring are alternatively 3.3819 and $3.5179 \AA$, while the centroids distances between the py planes $\left(\mathrm{C}_{\mathrm{g}}(\mathrm{py}) \cdots \mathrm{C}_{\mathrm{g}}(\mathrm{py})\right)$ are alternatively 3.7000 and $3.8782 \AA$. Such zipperlike

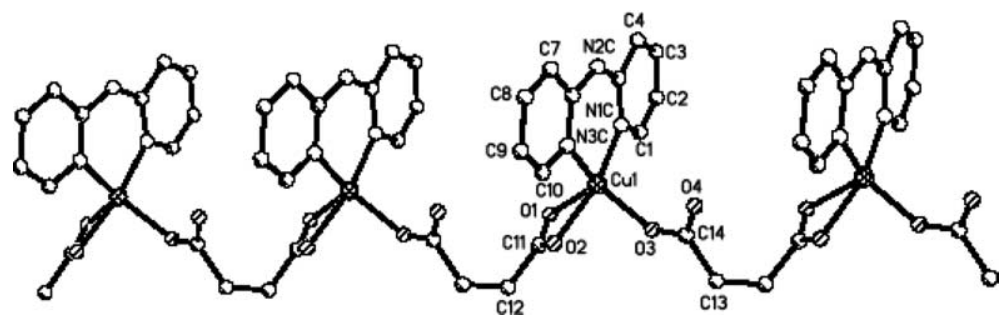

Fig. 1. Coordination environment of the $\mathrm{Cu}^{\mathrm{II}}$ atom in $\mathbf{1}$ with atomic labels.

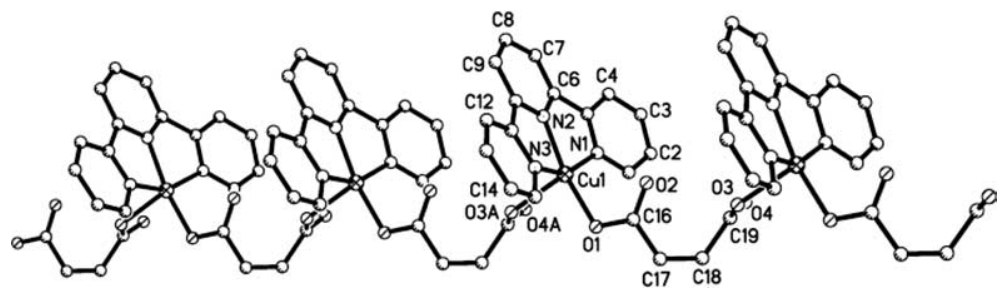

Fig. 2. Coordination environment of the $\mathrm{Cu}^{\mathrm{II}}$ atom in $\mathbf{2}$ with atomic labels. 


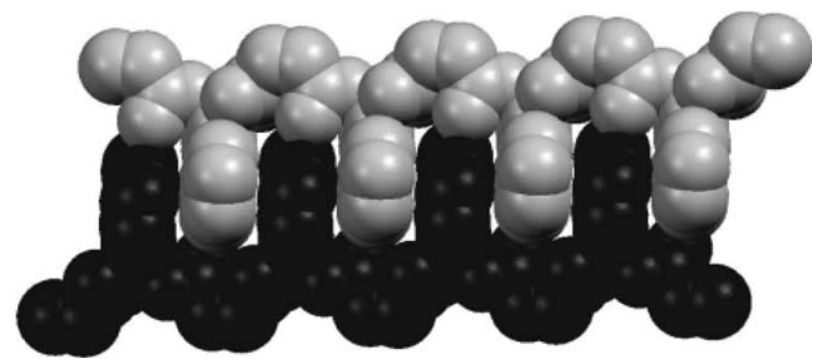

Fig. 3. Assemblies of $1 \mathrm{D}[\mathrm{Cu}(\mathrm{mal})(\mathrm{Hdpa})]_{n}$ polymeric chains via the $\pi-\pi$ stacking and $\mathrm{N}-\mathrm{H} \cdots \mathrm{O}$ hydrogen bonding interaction into double chains in 1 .

chain structures are notably common biochemically, but so far, few examples of zipperlike coordination polymer compounds have been reported $[8 \mathrm{~b}, 12]$. It is noteworthy that the zipperlike double chains reported mostly generate allowing for aromatic $\pi-\pi$ stacking interactions. But in 1, strong $\mathrm{N}-\mathrm{H} \cdots \mathrm{O}$ hydrogen bonds involving the adjacent uncoordinated dpa active amine $(-\mathrm{NH}-)$ and uncoordinated mal oxygen atoms (O4) (the distance of $\mathrm{N}-\mathrm{H} \cdots \mathrm{O}$ is $2.7950(2) \AA$ and the angle is $174.31^{\circ}$ ) render additional attractions between the pair of strands. To our knowledge, such double chains with strong $\mathrm{N}_{-}$ $\mathrm{H} \cdots \mathrm{O}$ hydrogen bonds have not been reported.

In addition, each double chain is surrounded by six other double chains and the adjacent double chains are connected to produce a $3 \mathrm{D}$ network via weak $\mathrm{C}-$ $\mathrm{H} \cdots \mathrm{O}$ hydrogen bonding interactions between the oxygen atom of maleate group and the carbon atom belonging to the adjacent double chain (the distances range from 3.2052(3)-3.5333(5) ^) (Fig. 4), as well as van der Waals forces.

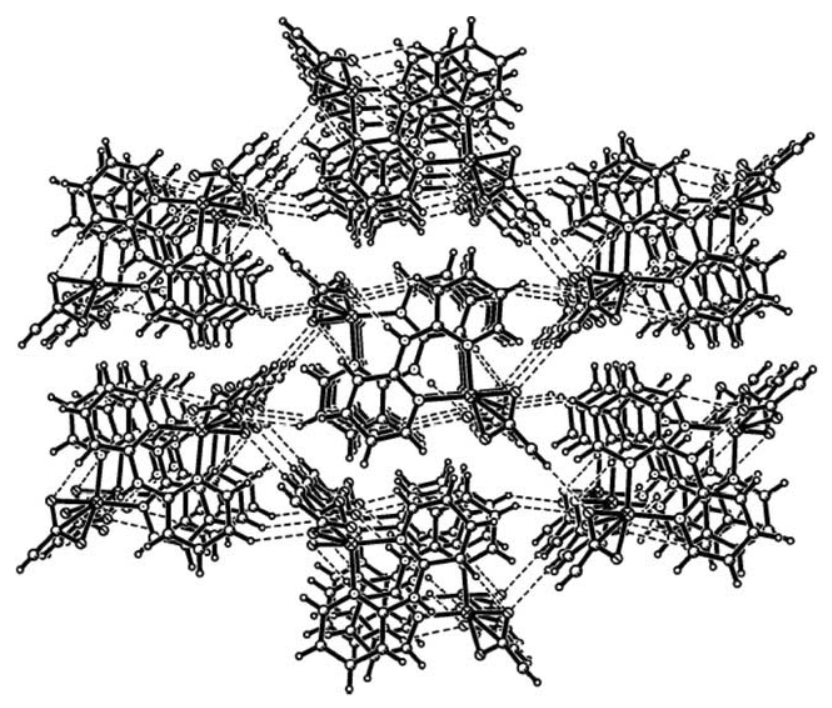

Fig. 4. Molecular packing diagram showing the double chains surrounded by six other chains through $\mathrm{H}$-bonding interactions in hexagonal arrangement in $\mathbf{1}$.
In contrast to $\mathbf{1}$, the adjacent chains in $\mathbf{2}$ are rearranged in zipperlike layers with the same directions of the chain axes. Within the crystal structure, two pyridine rings of tpy (comprising atoms $\mathrm{N} 1$ and $\mathrm{C} 1-\mathrm{C} 5$ is designated as ring 1 with centroid $\mathrm{C}_{\mathrm{g} 1}$ and $\mathrm{N} 3$ and $\mathrm{C} 11-\mathrm{C} 15$ as ring 2 with centroid $\mathrm{C}_{\mathrm{g} 2}$ ) involved in the intermolecular $\pi-\pi$ stacking interactions. Unlike dpa in 1, the two pyridine rings of tpy ligands respectively allow pairing of two symmetry-related pyridine rings of the adjacent single-stranded chains to generate a $2 \mathrm{D}$ zipperlike layers with the aromatic $\pi-\pi$ stacking interactions (Fig. 5). The perpendicular distances from $\mathrm{C}_{\mathrm{g} 1}$ to the plane of symmetry-related ring of the adjacent chain, and from $\mathrm{C}_{\mathrm{g} 2}$ to the plane of symmetry-related ring of the adjacent chain are $3.3371,3.5078 \AA$ and $3.3496,3.6331 \AA$, respectively, and the distances between the ring centroids $\left(\mathrm{C}_{\mathrm{g} 1}\right.$ and $\mathrm{C}_{\mathrm{g} 2}$ ) are $3.627,5.300 \AA$ and $3.747,4.224 \AA$, respectively. The dihedral angle from ring 1 to ring 2 is $20.9^{\circ}$. Additionally, the uncoordinated $\mathrm{O} 2$ and $\mathrm{O} 4$ acceptors of maleate ligand are engaged in significant hydrogenbonding interactions with carbon atoms of tpy with O ...C distances from 3.1240(2) to 3.4153(2) $\AA$, which render additional attractions between the adjacent strands. To the best of our knowledge, such zipperlike intercalations presents the first example of that the same orientated aromatic chelate ligands are simultaneously attached to both sides of the chain through aromatic $\pi-\pi$ stacking interactions to generate a $2 \mathrm{D}$ zipperlike layers.

The packing of the complex 2 is shown in Fig. 6. Each lay is interconnected through hydrogen bonds between maleate oxygen atoms and guest water molecules $\mathrm{O6w}$ to result in a 3D supramolecular network with $1 \mathrm{D}$ channel. Perpendicular to the layers, channels are observed and the void size is about $12.924 \times 8.329 \AA$ (Fig. 6(a)). An interesting feature is that an infinite chain of hydrogen-bonded water molecules passes through the channel

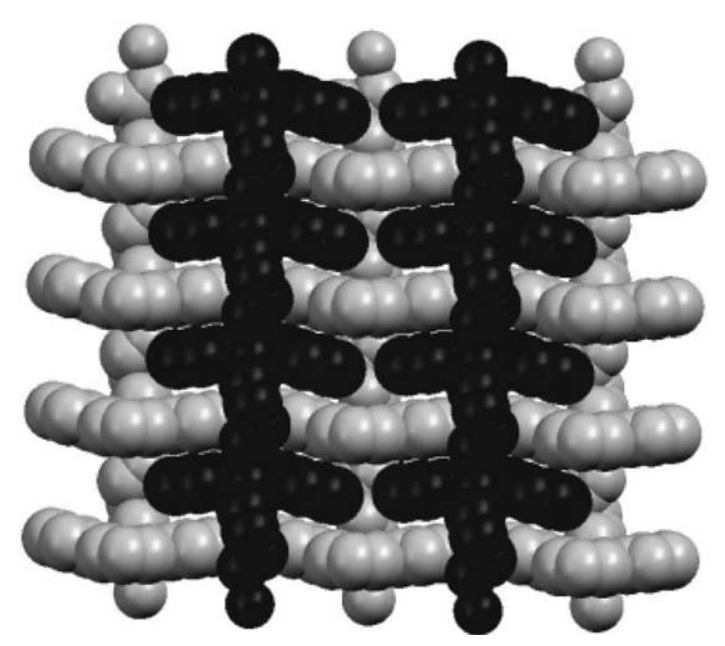

Fig. 5. Infinite 2D zipperlike layers view of complex 2 in the ac plane. 


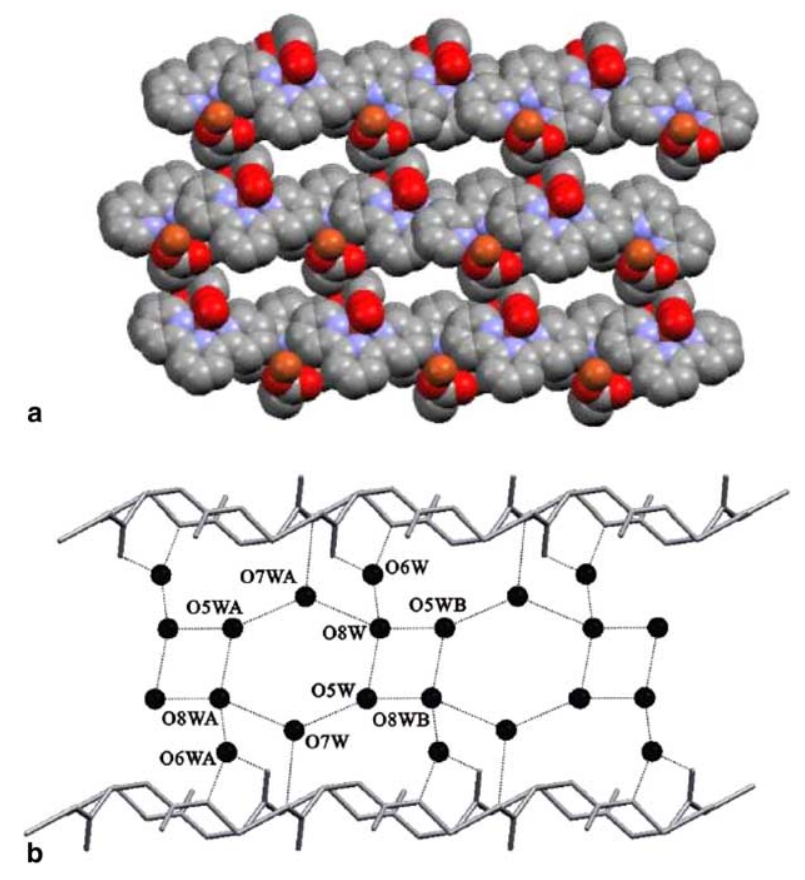

Fig. 6. (a) Space-filling model of $\mathbf{2}$ as viewed down the $b$ axis (guest water molecules and all hydrogen are omitted for clarity). (b) View of hydrogen-bonding 1D water chain of $\mathbf{2}$ in the channel (tpy ligands and all hydrogen are omitted for clarity).

in an unprecedented fashion (Fig. 6(b)). Unexpectedly, the infinite water chain is produced by alternate repetition of cyclic tetramer with one dangling water molecule and chair cyclic hexamer (Fig. 6(b)) with hydrogenbonding (2.8839(5), 2.8806(5), 3.0230(2), 2.7831(3),

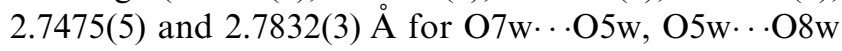
O7wA...O8 8 , O5w..O $8 w B, \quad$ O6w..O $8 w$ and O8w... O5wB, respectively) (Fig. 6(b)).

In the past decades, a variety of $1 \mathrm{D}$ polymeric water has been found in a number of crystal hosts, such as 1D segregated water chain [13], crankshaft chain [14], string-of-pearls motif [15]. The 1D water chain structures constituting a potentially important form of water is poorly understood [16]. Many fundamental biological processes appear to depend on the unique properties of water chains [17]. However, the knowledge of structural constraints required in the stabilization of water chains and the influence of the chain structure on the host remains incomplete [18]. The 1D water chains in $\mathbf{2}$ appear to be stabilized by 3D supramolecular network through the hydrogen bond with maleate oxygen atoms and the water molecules (2.7908(5), 2.8680(2) and 2.8324(2) for $\mathrm{O} 1 \cdots \mathrm{O} 6 \mathrm{w}, \mathrm{O} 4 \cdots \mathrm{O} 6 \mathrm{w}$ and $\mathrm{O} 7 \mathrm{w} \cdots \mathrm{O} 3$, respectively). This information of the 1D water chain is helpful in improving our understanding of the structures and characteristics of liquid water and ice, as well as in biological and chemical processes. Meanwhile, the degree of structuring of the water cluster that can be imposed by its environment, and vice versa, can be of importance in the design of new metal-organic framework (MOF) structures [19].

\subsection{Vibrational spectra}

The IR spectrum of 1 contains prominent $v(\mathrm{COO})_{\text {as }}$ and $v(\mathrm{COO})_{\mathrm{s}}$ stretching bands around 1658, 1562 and $1488,1433 \mathrm{~cm}^{-1}$, respectively. The $\Delta v$ values (170 and $129 \mathrm{~cm}^{-1}$ ) are close to the value expected for a unidentate coordination mode and a chelating coordination mode of the carboxylate moiety, respectively [20]. Complex 2 shows the strong bands corresponding to $v(\mathrm{COO})_{\text {as }}$ and $v(\mathrm{COO})_{\mathrm{s}}$ at 1592 and $1410 \mathrm{~cm}^{-1}$, respectively. The $\Delta v$ value is $180 \mathrm{~cm}^{-1}$, which is as expected for a unidentate coordination mode of the carboxylate moiety [20], suggesting that the carboxylate functions may be coordinated to the copper centers in a similar mode.

\subsection{Thermal analyses}

To study the thermal stability of complexes $\mathbf{1}$ and $\mathbf{2}$, thermogravimetric analyses and differential scanning calorimetry (TGA and DSC) were performed. The TGA results of 1 show that no obvious decomposition was observed until about $200^{\circ} \mathrm{C}$ and prove no water molecules in polymers. But the TG curves of 2 show the first stage of weight loss from 80 to $120^{\circ} \mathrm{C}$ is mainly due to the release of four water molecules per formula unit. The observed weight loss $(14.85 \% 2)$ is close to the calculated one $(14.91 \% 2)$, indicating that the weight loss of water molecules is consistent with the compounds described. Between 200 and $450^{\circ} \mathrm{C}$ the weight loss is noticeable for $\mathbf{1}$ and $\mathbf{2}$, accompanying amassing of heat, corresponding to the decomposition and oxidation of mal and aromatic chelate ligands. The final product of $\mathbf{1}$ and $\mathbf{2}$ is all $\mathrm{CuO}$. The experimental residual percentage weights $(23.08 \%$ for $\mathbf{1}$, and $16.66 \%$ for 2$)$ at the end of the decomposition of the polymers are consistent with the calculated values of $22.94 \%$ for $\mathbf{1}$ and $16.57 \%$ for $\mathbf{2}$.

\subsection{Magnetic property}

The magnetic susceptibilities of complexes $\mathbf{1}$ and $\mathbf{2}$ were measured in the temperature range $2-300 \mathrm{~K}$. The plots $\chi_{\mathrm{M}}$ and $1 / \chi_{\mathrm{M}}$ versus $T$ are shown in Figs. 7 and 8 for complexes 1 and 2, respectively. The plots of $1 / \chi_{M}$ versus $T$ obey the Curie-Weiss law $\left[\chi_{\mathrm{M}}=C /(T-\theta)\right]$ with positive Weiss constants of $\theta=2.18 \mathrm{~K}$ and $\theta=5.4 \mathrm{~K}$ and Curie constant $(C)$ values of 0.376 and $0.40 \mathrm{~cm}^{3} \mathrm{~K} \mathrm{~mol}^{-1}$ for complexes 1 and 2, respectively. In view of the known structure of the complexes, the experimentally determined magnetic behavior was fitted by use of Eq. (1) [3]. The best fitting parameters obtained are $g=2.02, J=0.14 \mathrm{~cm}^{-1}$, with an agreement factor $R=6.98 \times 10^{-4} \quad\left(R=\sum\left[\left(\chi_{\mathrm{M}} T\right)_{\mathrm{obs}}-\left(\chi_{\mathrm{M}} T\right)_{\mathrm{calc}}\right]^{2} /\right.$ 


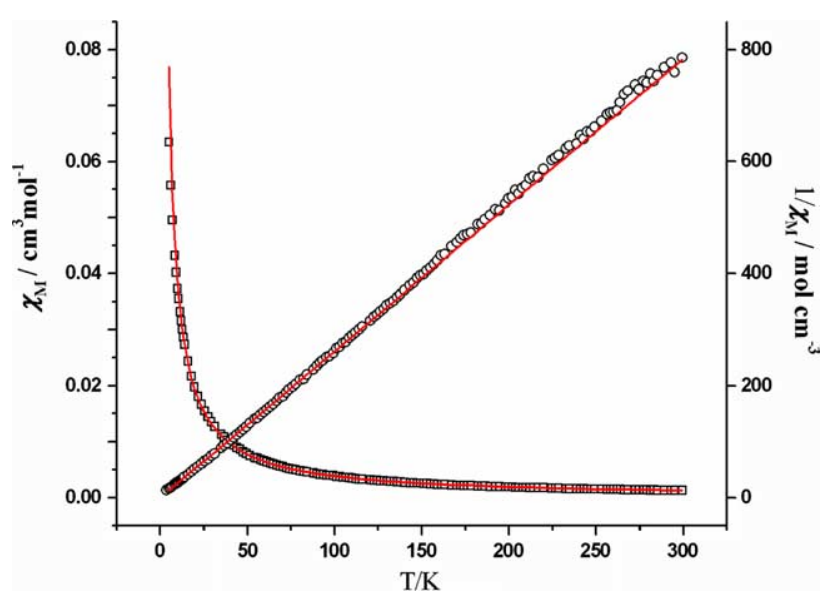

Fig. 7. Temperature dependent of $1 / \chi_{M}(\bigcirc)$ and $\chi_{M}(\square)$ for 1 (-: calculated curve).

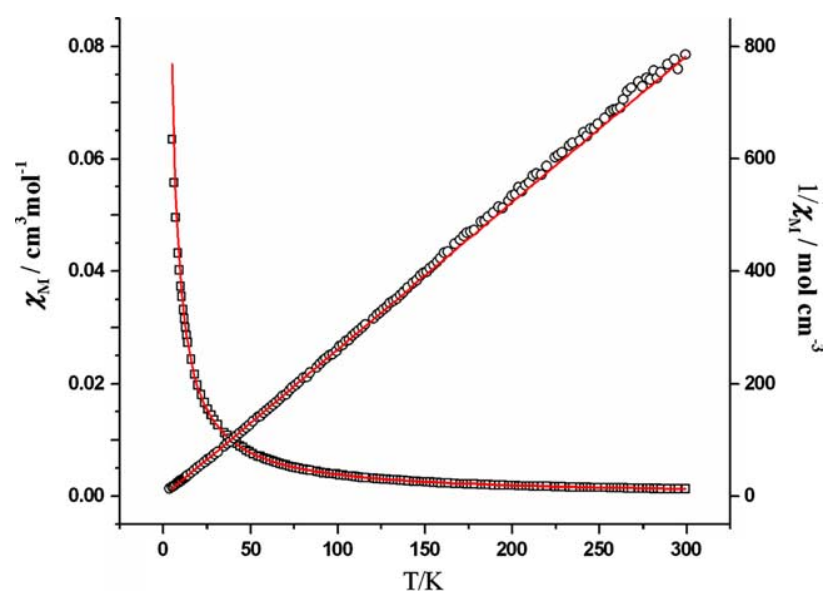

Fig. 8. Temperature dependent of $1 / \chi_{M}(\bigcirc)$ and $\chi_{M}(\square)$ for 2 (-: calculated curve).

$\left.\sum\left[\left(\chi_{\mathrm{M}} T\right)_{\mathrm{obs}}\right]^{2}\right)$ for $\mathbf{1}$, and $g=2.16, J=0.41 \mathrm{~cm}^{-1}$, with an agreement factor $R=2.08 \times 10^{-3}$ for $\mathbf{2}$. For both complexes $\mathbf{1}$ and $\mathbf{2}$, the fitting results all indicate the magnetic interactions between metal ions and the coordinated ligands are weak ferromagnetic interaction.

$\chi_{\mathrm{M}}^{\mathrm{J}}=\frac{N \beta^{2} g^{2} S(S+1)}{3 k T} \frac{1+u}{1-u}$

$u=\operatorname{coth}\left[\frac{J S(S+1)}{k T}\right]-\left[\frac{k T}{J S(S+1)}\right]$.

\section{Conclusions}

Two novel 1D polymeric chains with the general formula $\left\{[\mathrm{Cu}(\mathrm{mal}) \mathrm{L}] \cdot x\left(\mathrm{H}_{2} \mathrm{O}\right)\right\}_{n}\left(x=0,4 ; \mathrm{L}=2,2^{\prime}\right.$-dipyridylamine or $2,2^{\prime}: 6^{\prime}, 2^{\prime \prime}$-terpyridine) have been synthesized and characterized. These polymers are based on topologically identical chains where the copper centers chelated by amine ligands are linked by mal bridges. Substitution of $2,2^{\prime}$-dipyridylamine with $2,2^{\prime}: 6^{\prime}, 2^{\prime \prime}$-ter- pyridine resulted in significant differences in the coordination environment, coordination modes of the mal ligands and chain packing, which indicates the predominant structural role of aromatic-aromatic interactions and the steric effects of these ligands. An appropriate combination of dicarboxylate and aromatic chelate ligands may lead to the formation of zipperlike doublestranded chain or 3D supramolecular network with 1D open channels which are self-organized uniquely by supramolecualar recognition and attraction. More significantly, in 2, the host framework encapsulates unprecedented 1D water chain in the channel. Both polymers were magnetically characterized and interestingly show weak ferromagnetic behavior.

\section{Supplementary material}

Crystallographic data (excluding the structure factors) for the structure reported in this paper have been deposited with the Cambridge Crystallographic Data Centre as supplementary publication no. CCDC261646 (1) and CCDC-261647 (2). Copies of the data can be obtained free of charge on application to CCDC, 12 Union Road, Cambridge CB21EZ, UK, fax: +44 1223336 033, email: deposit@ccdc.cam.ac.uk.

\section{Acknowledgments}

The work was supported by the National Natural Science Foundation of China (No. 20471048) and "TRAPOYT".

\section{References}

[1] (a) H.K. Chae, D.Y. Siberio, J. Kim, Y. Go, M. Eddaoudi, A.J. Matzger, M. O'Keeffe, O.M. Yaghi, Nature 427 (2004) 523;

(b) J.S. Seo, D. Whang, H. Lee, S.I. Jun, J. Oh, Y.J. Jeon, K. Kim, Nature 404 (2000) 982.

[2] (a) E.Y. Lee, M.P. Suh, Angew. Chem., Int. Ed. 43 (2004) 2798; (b) J.C. MacDonald, P.C. Dorrestein, M.M. Pilley, M.M. Foote, J.L. Lundburg, R.W. Henning, A.J. Shultz, J.L. Manson, J. Am. Chem. Soc. 122 (2000) 11692;

(c) J.C. Noveron, M.S. Lah, R.E. Del Sesto, A.M. Arif, J.S. Miller, P.J. Stang, J. Am. Chem. Soc. 124 (2002) 6613.

[3] O. Kahn, Molecular Magnetism, VCH, New York, 1993.

[4] (a) T.F. Liu, H.L. Sun, S. Gao, S.W. Zhang, T.C. Lau, Inorg. Chem. 42 (2003) 4792;

(b) C. Ruiz-Pérez, M. Hernández-Molina, F. Lloret, J. Cano, M. Julve, Inorg. Chem. 39 (2000) 3845;

(c) C. Ruiz-Pérez, J. Sanchiz, M. Hernández-Molina, F. Lloret, M. Julve, Inorg. Chem. 39 (2000) 1363;

(d) J. Li, H. Zeng, J. Chen, Q. Wang, X. Wu, Chem. Commun. (1997) 1213.

[5] (a) Y.B. Go, X.Q. Wang, E.V. Anokhina, A.J. Jacobson, Inorg. Chem. 43 (2004) 5360;

(b) L. Deakin, A.M. Ariff, J.S. Miller, Inorg. Chem. 38 (1999) 5072; 
(c) M.-F.S. Lo, S.-Y.S. Chui, L.Y. Shek, Z. Lin, X.X. Zhang, G.H. Wen, I.D. Willams, J. Am. Chem. Soc. 122 (2000) 6293.

[6] (a) J.J. Girerd, O. Kahn, M. Verdaguer, Inorg. Chem. 19 (1980) 274

(b) M. Julve, M. Verdaguer, A. Gleizes, M. Philoche-Lavisalles, O. Kahn, Inorg. Chem. 23 (1984) 3808.

[7] (a) X.Y. Chen, W.Z. Shen, P. Cheng, S.P. Yan, D.Z. Liao, Z.H. Jiang, Z. Anorg. Allg. Chen. 629 (2003) 697;

(b) C.G. Zhang, C.X. Zhao, Z. Ma, D.Y. Yan, J. Coord. Chem. $52(2000) 87$;

(c) M.X. Li, G.Y. Xie, S.L. Jin, Y.D. Gu, M.Q. Chen, J. Liu, Z. $\mathrm{Xu}$, X.Z. You, Polyhedron 15 (1996) 535;

(d) Z. Shi, L.R. Zhang, S. Gao, G.Y. Yang, J. Hau, L. Gao, S.H. Feng, Inorg. Chem. 39 (2000) 1990.

[8] (a) X.M. Chen, G.F. Liu, Chem.-Eur. J. 8 (2002) 4811;

(b) G.F. Liu, B.H. Ye, Y.H. Ling, X.M. Chen, Chem. Commun. (2002) 1442;

(c) J.C. Yao, W. Huang, B. Li, S.H. Gou, Y. Xu, Inorg. Chem. Commun. 5 (2002) 711.

[9] J.Y. Lu, V. Schauss, Cryst. Eng. Commun. 4 (2002) 623.

[10] ShelXTl 5.03 (PC-Version), Program Library for Structure Solution and Molecular Graphics; Siemens Analytical Instruments Division, Madison, WI, 1995.
[11] A.W. Addison, T.N. Rao, J. Reedijk, J. Van Rijn, G.C. Verschoor, J. Chem. Soc., Dalton Trans. (1984) 1349.

[12] (a) Y.Q. Zheng, J. Sun, J.L. Lin, Z. Anorg. Allg. Chem. 626 (2000) 1501 ;

(b) X. Shi, G.S. Zhu, Q.R. Fang, G. Wu, G. Tian, R.W. Wang, D.L. Zhang, M. Xue, S.L. Qiu, Eur. J. Inorg. Chem. 1 (2004) 185

[13] B.Q. Ma, H.L. Sun, S. Gao, Angew. Chem., Int. Ed. 43 (2004) 1374.

[14] M.L. Fu, G.C. Guo, L.Z. Cai, Z.J. Zhang, J.S. Huang, Inorg. Chem. 44 (2005) 184.

[15] A.C. Warden, M. Warren, M.T.W. Hearn, L. Spiccia, Inorg. Chem. 43 (2004) 6936.

[16] G. Hummer, J.C. Rasaiah, J.P. Noworta, Nature 414 (2001) 188.

[17] K.M. Jude, S.K. Wright, C. Tu, D.N. Silverman, R.E. Viola, D.W. Christianson, Biochemistry 41 (2002) 2485.

[18] B.H. Ye, B.B. Ding, Y.Q. Weng, X.M. Chen, Inorg. Chem. 43 (2004) 6866.

[19] A. Michaelides, S. Skoulika, E.G. Bakalbassis, J. Mrozinski, Cryst. Growth Des. 3 (2003) 487.

[20] K. Nakamoto, Infrared and Raman Spectra of Inorganic and Coordination Compounds, Wiley, New York, 1978. 